\title{
Special issue: Proceedings of the XLVIIIth ISCEV annual symposium, Fremantle, Western Australia
}

\author{
Enid Chelva
}

Published online: 3 December 2010

(C) The Author(s) 2010. This article is published with open access at Springerlink.com

\author{
Guest editors \\ Enid Chelva \\ Dr. Steve Colley \\ Dr. Jane Khan \\ A/Prof. Timothy Lai \\ Prof. Ted Maddess \\ Prof. Atsushi Mizota
}

\section{Editorial}

This special issue of Documenta Ophthalmologica documents the proceedings of the XLVIIIth ISCEV Annual Symposium, held in Fremantle, Western Australia, from 6th to 10th November, 2010.

The two main symposium themes were "Electrophysiology, Genetics and Imaging in Retinal Disease" and "Stimulus Paradigms in Multifocal Electrophysiology", which were supported by Invited Lectures Prof. David Mackey, Prof. John Hecklenlively and Prof. Erich Sutter.

The ISCEV Keynote Lecture, "The cellular origin of different components of the electroretinogram", was presented by Prof. Trevor Lamb and the prestigious

\section{E. Chelva $(\square)$}

ISCEV 2010, Medical Technology and Physics,

Sir Charles Gairdner Hospital, Nedlands, WA 6009,

Australia

e-mail: enid.chelva@health.wa.gov.au
Emiko-Adachi Lecture, entitled "Establishment of the concept of new clinical entities-complete and incomplete CSNB and occult macular dystrophy", was delivered by past ISCEV President, Prof. Yozo Miyake.

The Symposium hosted a Special Session on "Extended Protocols", organised by Prof. Mitch Brigell, Prof. Mike Marmor and Prof. Eberhart Zrenner, and two pre-conference courses, "Clinical Electrophysiology of Vision (Human)", coordinated by Prof. Graham Holder, and "Animal Electrophysiology and Imaging", directed by Prof. Mathias Seeliger.

\section{Editorial notes}

1. The abstracts in this issue have been edited and reset to a standard format. The Scientific Program Committee has made every effort to respect the intended meaning in the original submissions and apologises for any inadvertent misinterpretation.

2. Abbreviations are defined within each abstract except for the following which are used without definition throughout: cpd-cycles per degree, EOG-electro-oculogram, ERG-electroretinogram, ISCEV-International Society for Clinical Electrophysiology of Vision, 1-cone-long-wavelength cone, m-cone-medium-wavelength cone, $\mathrm{mf}$-multifocal, when used in conjunction with ERG, PERG, PhNR, OP or VEP, OP-oscillatory 
potential, PERG-pattern electroretinogram, $\mathrm{PhNR}$ - photopic negative response ERG, s-cone-short-wavelength cone, VEP_-visual evoked potential.

\section{Enid Chelva}
Chair,
Scientific
Program
Committee.

Open Access This article is distributed under the terms of the Creative Commons Attribution Noncommercial License which permits any noncommercial use, distribution, and reproduction in any medium, provided the original author(s) and source are credited.

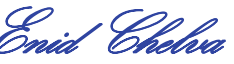

